
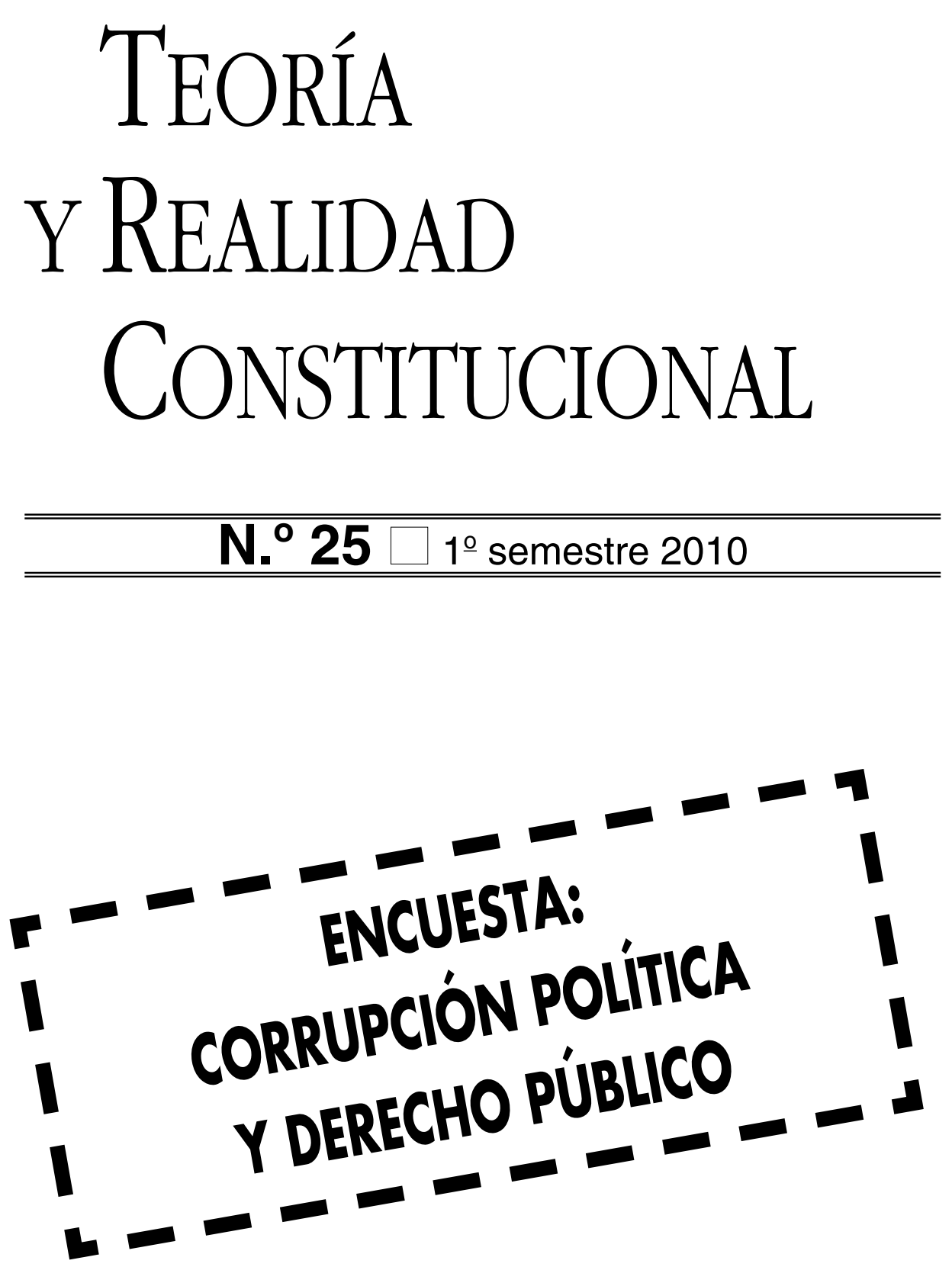


\title{
EL REFERÉNDUM SUIZO SOBRE LA PROHIBICIÓN DE MINARETES*
}

\author{
ANNE PETERS \\ Catedrática de Derecho Internacional Público y Derecho Constitucional \\ Universidad de Basilea
}

\section{SUMARIO}

I. El contexto constitucional del referéndum.

II. La prohibición en clave interna; posibles soluciones.

III. Demandas individuales ante el Tribunal Europeo de Derechos Humanos.

IV. El debate constitucional sobre el Derecho internacional como límite a las iniciativas populares.

V. ¿Y ahora?

\section{EL CONTEXTO CONSTITUCIONAL DEL REFERÉNDUM}

El 29 de noviembre de 2009 el pueblo suizo aprobó en referéndum la prohibición de la construir minaretes en el territorio del país. La iniciativa fue apoyada por el $57,8 \%$ de la población total y por veintidós ${ }^{1}$ de los veintiséis cantones. La participación, elevada para las pautas habituales, fue de un $53,4 \%$ del censo.

En la actualidad existen cuatro minaretes en Suiza, encontrándose pendiente de aprobación la solicitud de construcción de un quinto. Las consecuencias jurídicas del referéndum respecto de esta solicitud pendiente no son del todo evidentes, pero resultan claras frente a ulteriores pre-

* Traducción de F. Reviriego Picón, Profesor Titular de Derecho Constitucional de la UNED.

1 Diecisiete cantones y cinco semi-cantones, que cuentan con un solo voto en la segunda cámara. 
tensiones: como consecuencia del referéndum se insertará en la Constitución Federal Suiza ${ }^{2}$ un nuevo precepto que entrará inmediatamente en vigor. El nuevo artículo 72.3 rezará: «La construcción de minaretes está prohibida".

Dicho referéndum fue promovido en abril de 2007 a través de una iniciativa popular suscrita por dieciséis personas, catorce de las cuales pertenecían al "Schweizerische Volkspartei", cuyo programa político es claramente contrario a los procesos de inmigración. La Constitución exige, en su artículo 139, que una iniciativa popular de reforma constitucional sea avalada por cien mil firmas (la población del país ronda los siete millones) recogidas en un plazo de dieciocho meses. Cumplimentar tal requisito no supuso problema alguno en el caso de la iniciativa contra los minaretes: en julio de 2008 se había obtenido el respaldo necesario para proseguir su tramitación.

Verificadas y controladas las firmas así como su proceso de recogida, se procedió a cotejar la validez material de la iniciativa antes de proceder, en su caso y como así se hizo finalmente, a la convocatoria de referéndum: se encuentran prohibidas las iniciativas populares que no respeten las "disposiciones imperativas de derecho internacional" (art. 139.2); corresponde a la Asamblea Federal examinar esta cuestión ex art. 173.1.f del texto constitucional. La atribución de dicho control a la Asamblea Federal y no al Tribunal Federal encuentra su razón de ser, sin duda, en el respeto a la soberanía popular. Conforme la voluntad de los constituyentes, el veredicto de inadmisibilidad de una iniciativa, que obviamente limita o recorta la soberanía popular, sólo debería ser pronunciado por aquel cuerpo que disfruta de la legitimidad democrática más directa; la Asamblea Federal se compone de los representantes elegidos democráticamente mediante sufragio, en tanto que los miembros del Tribunal Federal —autoridad judicial suprema de la Federación (art. 188 Const.) — la tendrían, todo lo más, de forma más indirecta (los jueces que lo componen son elegidos por la Asamblea).

En el caso de la denominada "iniciativa antiminarete" la decisión parlamentaria era sencilla, pues aquella afectaba a la libertad religiosa tal y como se encuentra reconocida en la propia Constitución (art. 15), así como en el Convenio Europeo de Derechos Humanos (art. 9 CEDH) o en el Pacto Internacional de Derechos Civiles y Políticos (art 18 PIDCP). También en las más genéricas prohibiciones de discriminación que podemos ver en estos dos últimos (art. 14 CEDH y 2.1 PIDCP). En Latinoamérica (mas no a nivel mundial) se aprecia una tendencia a calificar las prohibiciones de discriminación como normas de Derecho internacional imperativo. ${ }^{3}$ Sin embargo, resulta claro que

2 La versión autentica de la Constitución suiza de 18 de abril de 1999, en lenguas alemana, francesa e italiana, puede encontrarse en http://www.admin.ch/. Una traducción oficial al inglés está disponible en la misma página.

3 Corte Interamericana de Derechos Humanos, opinión consultiva oc-18/03 de 17 de septiembre de 2003, solicitada por los Estados Unidos Mexicanos, sobre condición jurídica y derechos de los migrantes indocumentados, "par. 101 : En concordancia con ello, este Tribunal considera que el principio de igualdad ante la ley, igual protección ante la ley y no discrimina- 
la libertad religiosa no pertenece al cuerpo de ius cogens, tal como es definido en el derecho internacional, aceptado por la práctica suiza, ya que un elevado número de países no reconoce la libertad religiosa, y muchos han sometido reservas en esta materia en los instrumentos de derechos humanos universales. En la Resolución Parlamentaria sobre la admisibilidad de esta iniciativa popular ${ }^{4}$, la Asamblea Federal destacó que la adopción de esta iniciativa supondría una violación del derecho internacional, aunque, pese a ello, carecía del poder de declarar la inadmisibilidad de la iniciativa al quedar limitada al referido ius cogens.

La iniciativa tuvo que ser, por tanto, sometida a la decisión popular, celebrándose en la fecha antes apuntada. Durante la campaña, la mayor parte de los partidos políticos así como el propio gobierno solicitaron el voto en contra de dicha propuesta, no pudiendo anticiparse el resultado que finalmente darían las urnas, ciertamente sorprendente. Quizá cabría interpretar, a la vista de la claridad del resultado, que existe una cierta relación entre el mismo y un miedo, difuso pero extendido, de islamización en la sociedad. Es interesante apuntar que el resultado vino acompañado igualmente del anuncio de la propuesta, por parte del partido que había apoyado la iniciativa, de someter a nuevo referéndum la prohibición de vestir burkas en público.

\section{LA PROHIBICIÓN EN CLAVE INTERNA: POSIBLES SOLUCIONES}

No es aventurado señalar que se plantearán desafíos a esta prohibición con las solicitudes de construcción de minaretes que no tardarán en sucederse. ${ }^{5}$ Estas, lógicamente, habrán de ser denegadas, a causa de la nueva prohibición constitucional, por las autoridades locales competentes.

Agotados los recursos correspondientes será posible interponer, en su caso, una cuestión constitucional ante el Tribunal Federal en la que sin duda se alegará que dicha prohibición vulnera su libertad religiosa. El Tribunal Federal, a la vista de la nueva disposición, carecerá de margen de discreción alguno para la resolución de tal conflicto. Nos encontraremos por tanto ante una restricción constitucional del derecho a la libertad religiosa y de la prohibición de no discriminación por razón de religión contenidas respectivamen-

ción, pertenece al jus cogens, puesto que sobre él descansa todo el andamiaje jurídico del orden público nacional e internacional y es un principio fundamental que permea todo ordenamiento jurídico".

4 Parlamento Federal, Resolución sobre la admisibilidad de la iniciativa, Bundesblatt, 2009, pág. 4381. Véase también el Mensaje del Government Federal Council (Bundesblatt, 2008, pág. 7603) de 27 de agosto de 2008.

5 Rechazando el amparo abstracto contra el contenido de la iniciativa adoptada en referendum cfr. ya Schweizerisches Bundesgericht, Sentencias 1C_527/2009 y 1C_529/2009, ambas del 14 de diciembre de 2009. 
te en los artículos 15 y 8.2 del texto constitucional ${ }^{6}$. Si bien hasta la fecha, la noción de "norma constitucional inconstitucional" no se aceptaba, lo cierto es que la prohibición de minaretes se ha adoptado con una clara intención restrictiva limitadora de derechos que no permite solución de equilibrio alguna en orden a resolver el conflicto entre los dos preceptos constitucionales apuntados.

Es cierto que el Tribunal Federal suizo, en un caso anterior de conflicto entre una ley federal ordinaria y el CEDH, declaró inaplicable la ley contraria al Convenio. ${ }^{7}$ Pero esta jurisprudencia no debería ser trasladable a las normas constitucionales, porque éstas se sitúan en un rango normativo superior. Ante todo, en el caso de la iniciativa contra los minaretes el pueblo, en cuanto poder de reforma de la Constitución, ha asumido conscientemente la existencia de una infracción del $\mathrm{CEDH}$ (durante la campaña, los ciudadanos con derecho a voto fueron informados al respecto por parte de la administración federal). Hasta ahora, cuando el Parlamento se apartaba de modo consciente de las prescripciones contenidas en los Tratados internacionales, el Tribunal Federal lo aceptaba, manteniendo vigentes las Leyes promulgadas a sabiendas de su incompatibilidad con el Derecho internacional. ${ }^{8}$ Es fácil suponer que el Tribunal Federal mantendrá tal deferencia judicial, con mayor motivo en este caso, frente al poder soberano.

La falta de ratificación del Protocolo Facultativo $\mathrm{n}^{\circ} 1$ del PIDCP determina, como es sabido, la imposibilidad de que los particulares puedan presentar comunicaciones ante el Comité de Derechos Humanos de Naciones Unidas.

\section{DEMANDAS INDIVIDUALES ANTE EL TRIBUNAL EUROPEO DE DERECHOS HUMANOS}

Agotadas las vías de recurso internas, esto es, una vez dicte su fallo del Tribunal Federal, será posible la presentación, en el plazo de seis meses, de demandas individuales ante el Tribunal Europeo de Derechos Humanos (arts. 34-35 CEDH). Las excepciones a la exigencia del agotamiento de la vía judicial previa aceptadas por el TEDH no pueden ser invocadas en este caso. El Tribunal de Estrasburgo ha estimado demandas cuando es patente que acudir

6 "Art. 15. 1. Se garantiza la libertad de conciencia y religión. 2. Toda persona tiene derecho a elegir libremente sus creencias religiosas, así como a formarse sus propias convicciones filosóficas y a profesarlas individual o colectivamente. 3. Toda persona tiene derecho de adherirse o pertenecer a una comunidad religiosa así como de recibir sus enseñanzas. 4. Nadie puede ser obligado a adherirse o pertenecer a una comunidad religiosa, así como de recibir sus enseñanzas." "Art. 8.2. Nadie puede ser discriminado por razón de (...) creencias religiosas (...)".

7 Schweizerisches Bundesgericht, BGE 125 II 417 (1999) - A. v. Schweizerische Bundesanwaltschaft, Eidgenössisches Justiz- und Polizeidepartement und Schweizerischen Bundesrat (llamado caso $P K K)$.

8 Schweizerisches Bundesgericht, BGE 99 IB 39 (1973) - Schubert v. Commissione cantonale ticinese di ricorso. 
a las sucesivas instancias nacionales no ofrece perspectiva alguna de éxito, pero esto sólo ocurre cuando la cuestión disputada ha sido respondida negativamente en la jurisprudencia constante de los Tribunales nacionales. Esta no es la situación que aquí se da, dado que la cuestión jurídica resulta completamente novedosa. Tampoco concurren los supuestos de la otra excepción existente al agotamiento de la vía judicial previa en el ámbito nacional, que exige una lesión gravísima de derechos humanos y la disfuncionalidad de la justicia estatal.

No es aventurado señalar que el Tribunal de Estrasburgo declare en su momento que la prohibición de minaretes supone una violación del artículo $9 \mathrm{CEDH}$ considerado individualmente o en conjunción con el artículo 14. El hecho de que la infracción del Convenio provenga de una norma constitucional carece de relevancia. El Tribunal ya ha declarado anteriormente que determinadas prescripciones de una Constitución estatal eran contrarias al CEDH. ${ }^{9}$ El alcance del derecho de ejercer la libertad religiosa ha venido siendo interpretado hasta la fecha de forma amplia por el Tribunal de Estrasburgo. Aunque no resulten protegidos todos y cada uno de los actos o actividades que pudieran venir motivados o inspirados por una religión o creencia $^{10}$, lo cierto es que no solo lo son aquellas actividades o instrumentos que son estrictamente necesarios para el ejercicio de creencia disfrutan de la protección. Algunos ejemplos pueden ilustrarlo perfectamente: interfiere con la libertad religiosa imposibilitar el cumplimiento de rituales religiosos vinculados a temas alimenticias, así, en el caso conocido por el TEDH relativo a las comunidades ortodoxas judías ${ }^{11}$; también interferirían con aquella las prohibiciones gubernamentales para construir o alquilar edificios para usos religiosos ${ }^{12}$. A la vista de ello resulta por tanto indiferente que el culto islámico pueda practicarse en ausencia de minaretes si los propios musulmanes consideran que este forma parte de la expresión de sus creencias religiosas. ${ }^{13}$

9 STEDH, de 22 diciembre 2009 (Gran Cámara), Sejdić y Finci v. Bosnia Hercegovina (appl. No 27996/06 y 34836/06) sobre la infracción de la prohibición de discriminación por parte de algunas prescripciones de la Constitución de Bosnia-Herzegovina que preveían cuotas para los grupos étnicos en la ocupación de puestos oficiales del Estado.

10 STEDH, de 10 de noviembre de 2005 (Gran Cámara), Leyla Sabin v. Turkey (appl. $\mathrm{n}^{\circ}$ 44774/98), par. 105.

11 STEDH, de 27 de junio de 2000, Cha'are Shalom Ve Tsedek v. France (appl. n 27417/95), par. 80 .

12 Comisión Europea de Derechos Humanos, de 8 de marzo de 1994, Iskcon y otros $v$. the United Kingdom (appl. n $\mathrm{n}^{\circ}$ 20490/92); STEDH, de 26 de septiembre de 1996, Manoussakis and Others v. Greece (appl. no 59/1995/565/651), par. 36; STEDH, de 24 de junio de 2004, Vergos v. Greece (appl. n० 65501/01), par. 32.

13 Cfr. Schweizerisches Bundesgericht, BGE 135 I 79, de 24 de octubre de 2008, par. 4.4: El Tribunal no puede determinar por sí mismo el significado de un precepto religioso. Debe más bien partir del significado que tiene la norma religiosa para los demandantes de amparo (en torno al precepto islámico que prohíbe contemplar los atractivos del otro sexo y que por ello impide a los niños musulmanes participar en clases mixtas de natación). 
El derecho a la libertad religiosa no es desde luego absoluto. La prohibición de minaretes podría estar justificada si persiguiera uno de los objetivos legítimos mencionados en el artículo 9.2 CEDH y existiera proporcionalidad en la limitación, así, por ejemplo, que fuere «necesario en una sociedad democrática". Los defensores de la iniciativa popular han argumentado que la prohibición de minaretes tiene como objetivo el mantenimiento del orden público. Este objetivo, junto con el interés público del Estado en la planificación y ordenación del territorio, venía con frecuencia siendo aceptado por el Tribunal de Estrasburgo en casos que conciernen la restricción de actividades religiosas ${ }^{14}$. Pero la estricta prohibición de minaretes, sin ninguna excepción, no parece en modo alguno necesaria en orden a esa protección del orden público en tanto que las normas existentes en materia de planificación y construcción contienen los instrumentos necesarios para poder prohibir minaretes allí donde estos pudieran implicar molestias al vecindario. La normativa vigente podría asimismo utilizarse en orden a limitar su altura o impedir la contratación de un concreto almuecín. Existiendo, por tanto, instrumentos legales suficientes para la protección del orden público, una prohibición absoluta como la articulada con el referéndum resulta desproporcionada e innecesaria en los términos del art. 9.2 CEDH.

A diferencia de lo que ocurre con los velos portados por profesoras o la instalación de crucifijos en escuelas públicas, el mensaje religioso de los minaretes no puede ser interpretado desde la perspectiva de la influencia que pueden provocar de forma necesaria (en los estudiantes - menores-). No existe, como en aquellos casos en donde los estudiantes perciben al profesor como autoridad y existen a símbolos religiosos en las aulas, un derecho de la población no musulmana a extraer del (negativo) de su libertad religiosa la inexistencia de minaretes en sus ciudades.

Estos rasgos (la ausencia de un ajuste educativo y la protección de una minoría ${ }^{15}$ ) distinguen este caso frente a los anteriores. La Convención Europea permite que los países miembros puedan prohibir velos en escuelas y universidades $^{16}$ (en Turquía incluso los portados por estudiantes ${ }^{17}$ ), y a la inversa no permite (Italia) que se muestren crucifijos (símbolo de la creencia religiosa mayoritaria en ese país) en las escuelas públicas ${ }^{18}$.

14 STEDH, de 24 de junio de 2004, Vergos v. Greece (appl. n ${ }^{\circ}$ 65501/01), par. 40.

15 La prohibición de discriminación articulada por el TEDH es "simétrica", no protegiendo únicamente minorías o miembros de grupos oprimidos, así, por ejemplo, también lo haría con personas de raza blanca (A. PETERS / D. KÖNIG, Kapitel 21: Das Diskriminierungsverbot, en R. GROTE / TH. MARAUHN (eds.), EMRK/GG: Konkordanzkommentar, Tübingen: Mohr Siebeck 2. ed. 2010, \$\$ 66-67). No obstante, el hecho de que un grupo minoritario sea perjudicado por una ley singular debería tener un impacto en la decisión de equilibrio.

16 STEDH, Dablab v. Suisse, decision de inadmisión de 15 de febrero de 2001 (appl. $n^{\circ}$ 42393/98): La prohibición del Cantón suizo de Ginebra de portar velos por una profesora de una escuela primaria es conforme al artículo 9 del CEDH.

17 STEDH, de 10 de noviembre de 2005, Leyla Sabin v Turkey (appl. no 44774/98).

18 STEDH, Lautsi v Italie, de 3 de noviembre de 2009 (appl. no 30814/06): la exhibición de crucifijos en las aulas supone una violación del artículo 2 del Protocolo 1 y del artículo 9 del Convenio. 
Además, la libertad religiosa tal y como está garantizada por el CEDH contiene un fuerte componente de neutralidad religiosa, imparcialidad y tolerancia $^{19}$. El TEDH con frecuencia ha venido destacando el papel del Estado como el organizador neutro e imparcial del ejercicio de diferentes religiones o creencias, declarando que este papel es garante del orden público, la armonía religiosa y la tolerancia en una sociedad democrática; ello lleva a que ese deber de neutralidad e imparcialidad sea incompatible con la evaluación de la legitimidad de las creencias religiosas o las vías por las que estas se manifiestan $^{20}$. La prohibición de minaretes se dirige de forma exclusiva contra el Islam. El hecho que esta religión sea una suerte de "recién llegada" en la sociedad suiza no puede servir de excusa para que el Estado la trate de manera diferente a las religiones más tradicionales.

Finalmente, el Tribunal Europeo de Derechos Humanos ha venido insistiendo cada vez más en «el verdadero pluralismo religioso, que resulta vital para la supervivencia de una sociedad democrática", como un principio básico en los debates en que está en juego la libertad religiosa ${ }^{21}$. Los países, según la jurisprudencia del Tribunal, deben asegurar la tolerancia mutua entre los diferentes grupos y comunidades ${ }^{22}$. En consecuencia, la respuesta de las autoridades en los casos de coexistencia de diversos grupos religiosos no puede ser la eliminación del pluralismo para evitar las posibles tensiones, sino asegurar la tolerancia entre unos y otros ${ }^{23}$. Debe alcanzarse así el equilibro con un tratamiento adecuado de las minorías religiosas, impidiendo los abusos de las mayorías ${ }^{24}$.

El Tribunal de Estrasburgo también tendrá que examinar en consecuencia si la prohibición de minaretes, que singulariza una religión particular, es una violación del artículo 9 del CEDH en conjunción con el artículo 14 del mismo texto. El diferente tratamiento asentado en cuestiones religiosas está prohibido salvo que se proporcione una justificación objetiva y razonable. El Tribunal ha venido aplicando así un estricto escrutinio en estos casos y exige razones de peso en orden a justificar el tratamiento diferencial de personas o grupos basados en sus creencias religiosas ${ }^{25}$. En el caso de la prohibición de minaretes no parecen existir tales motivos.

El Convenio Europeo de Derechos Humanos ha concedido los Estados miembros un margen de apreciación en casos que conciernen a la libertad religiosa ${ }^{26}$, y también en el campo de planificación y dirección del territo-

19 Véase, ejemplificativamente, STEDH, de 13 de diciembre de2001, Metropolitan Church of Bessarabia and Others v. Moldova, (appl. $\mathrm{n}^{\circ}$ 45701/99) par. 123.

20 STEDH, de 10 de noviembre de 2005 (Gran Cámara), Leyla Sabin v. Turkey (appl. n 44774/98), par. 107.

21 Ibid., par. 110.

22 Ibid., par. 107.

23 Ibid., par. 107.

24 Ibid., para. 108.

25 STEDH, Hoffmann v. Austria, de 23 junio de 1993 (appl. no 12875/87), S. A 255-C, par. 36.

26 STEDH, de 10 de noviembre de 2005, Leyla Sahin v. Turkey (appl. no 44774/98), par. 109110, que concluyó que la prohibición turca de portar velos en edificios públicos se encontraba dentro del margen posible de apreciación. 
rio $^{27}$. Cabría preguntarse si el margen de apreciación debería entenderse de forma amplia sobre la base de haber sido adoptado en referéndum. Pero lo cierto es que la democracia directa no tiene per se más valor que la representativa, y por lo tanto ello no debería habilitar la posibilidad de restringir o limitar más los derechos en aquellos casos en que la decisión se tomara por referéndum que frente a una mera decisión parlamentaria. Dicho margen parece haber sido sobrepasado en el presente caso.

La eventual decisión del Tribunal de Estrasburgo deberá determinar la necesidad de adecuar la normativa suiza de conformidad a lo previsto en el Convenio (art. $46 \mathrm{CEDH}$ ). Habrá de reformarse nuevamente la Constitución para eliminar o mitigar dicha prohibición; el Comité de Ministros del Consejo de Europa deberá supervisar todo este proceso. Tras una condena de Estrasburgo, Suiza bien podría seguir el ejemplo de Alemania y limitarse simplemente a "tomar en consideración" la sentencia del TEDH en el marco de los principios constitucionales suizos. Si el postulado de la soberanía popular se valora como principio central del orden constitucional, los órganos estatales suizos podrían, en consonancia con la sentencia Görgülü del Tribunal Constitucional alemán ${ }^{28}$, rechazar la ejecución de la sentencia del TEDH. Desde la perspectiva del Consejo de Europa ello seguiría siendo, en cualquier caso, contrario al CEDH.

La opción política de denunciar el Convenio, posible como es sabido al amparo del artículo 58 del mismo, no parece viable. Volver de inmediato a ratificar el Convenio ahora con una reserva, por ejemplo bajo la forma de una "reserva de garantía del núcleo constitucional", parece igualmente ilusorio. La estrategia alternativa de rechazar la aplicación de una decisión del Tribunal de Estrasburgo y resistir la presión de este organismo y de la opinión pública parece cerrada. Suiza ostenta en este momento la presidencia del Comité de Ministros en el Consejo de Europa y siempre ha manifestado su apoyo al Consejo de Europa y su régimen, especialmente porque Suiza no es miembro de la Unión Europea.

\section{EL DEBATE CONSTITUCIONAL SOBRE EL DERECHO INTERNACIONAL COMO LÍMITE A LAS INICIATIVAS POPULARES}

El referéndum reavivará sin duda el debate existente desde tiempo atrás acerca de la admisibilidad o inadmisibilidad de las iniciativas populares que impliquen la adopción de previsiones constitucionales que violen el derecho internacional. Tanto en sede doctrinal como política se ha discutido sobre la extensión de las limitaciones constitucionales sobre iniciativas populares.

27 STEDH, de 24 de junio de 2004, Vergos $v$. Greece (appl. n 65501/01), par. 42.

28 BVerfGE 111, 307 (2004). 
Así, se ha aconsejado calificar la normativa internacional en materia de derechos humanos internacionales como "normas perentorias de facto", pues la aplicación de leyes que violen garantías de derechos humanos internacionales sería de facto imposible. Pero las propuestas de contemplar la cláusula de limitación constitucional del artículo 139.2 de la Constitución de una forma tan extensa no se adecúa con la clara previsión establecida ni con la intencionalidad del constituyente de 1999 de poner pocas trabas a las iniciativas populares.

Es por ello que la sugerencia doctrinal más adecuada no es otra que articular en sede constitucional la prohibición de iniciativas que supongan una clara violación de derechos humanos. Sin embargo, tal prohibición requeriría la previa reforma constitucional que precisaría en consecuencia de forma preceptiva la celebración de un referéndum; optar por esa vía por tanto, parece casi inviable. Otro problema subyacente en las iniciativas federales populares es que la capacidad de decidir la admisibilidad de una iniciativa se asienta en el parlamento. Pero tales límites claramente atañen a cuestiones legales y no a cuestiones esencialmente políticas. Los parlamentarios no están completamente capacitados para resolver tales cuestiones, teniendo una clara renuencia a pronunciarse en contra de lo manifestado por un amplio segmento de la ciudadanía, así, cuando menos, cien mil ciudadanos.El parlamento no parece el órgano más apropiado para realizar la tarea de escudriñar la admisibilidad de iniciativas populares.

En la medida en que no cabe plantear una iniciativa para la adopción de una ley ordinaria federal mientras que sí resulta posible para una reforma constitucional, nos encontramos con previsiones constitucionales como la abordada en estas notas sobre la prohibición de los minaretes que, en su caso, tendría a priori mejor acomodo legal, pues cuestiones de este tenor (más allá de su valoración última) parece que no debe formar parte de lo que de ordinario se considera o puede considerar materia constitucional.

\section{V. ¿Y AHORA?}

No está exento de riesgo buscar en instancias internacionales el remedio frente a decisiones democráticas (directas) de la mayoría que producen «daños sustanciales colaterales". Cualquier fallo del Tribunal Europeo de Derechos Humanos contrario a Suiza no hará sino alimentar en la ciudadanía el sentimiento y la sospecha frente a un "gobierno de jueces extranjero". En los últimos tiempos, la tensión entre la democracia directa y el respeto a los derechos humanos garantizados en sede internacional se pone de manifiesto. La tarea de reconciliar soberanía popular e imperio de la ley parece una historia interminable. 
TITLE: The Swiss Referendum on the probibition on minarets.

ABSTRACT: The article analyzes the implications of the Swiss referendum on the probibition of minarets that took place in November, 2009, after a brief study of the procedure foreseen in the Constitution which allows for popular initiatives leading to referendums such as the present one.

RESUMEN: El artículo analiza las implicaciones del referéndum suizo sobre la probibición de minaretes celebrado en noviembre de 2009 tras un breve estudio del procedimiento habilitado en el ordenamiento federal en orden a articular iniciativas populares como la que está en el origen del presente referéndum.

KEYWORDS: Referendum. Minarets. International Law. Human Rights.

Palabras Clave: Referendum. Minaretes. Derecho Internacional. Derechos Humanos. 